\title{
Analysis of tyrosinase synthesis in Streptomyces antibioticus
}

\author{
Aline M. Betancourt, Valerie Bernan, $\dagger$ Wayne Herber $\ddagger$ and Edward Katz* \\ Department of Microbiology, Georgetown University Medical School, 3900 Reservoir Road, NW, \\ Washington, DC 20007, USA
}

(Received 20 August 1991; revised 28 November 1991; accepted 30 December 1991)

\begin{abstract}
${ }^{35}$ S-labelling experiments and Western blot analysis were used to investigate methionine induction of tyrosinase synthesis in Streptomyces antibioticus. De novo synthesis of the enzyme occurred as a function of time and methionine concentration. Induction appeared to be relatively specific for methionine and closely related analogues. Under the conditions used, the enzyme was secreted rapidly, with little intracellular accumulation. Upon induction in the absence of $\mathrm{Cu}^{2+}$, apotyrosinase was synthesized at $70 \%$ of the level in control cultures provided with the cation. Inhibitor studies showed that both transcriptional and translational events are required for tyrosinase induction. Deletions in the ORF 438 region of the mel operon suggest that this sequence has a role in the phenotypic expression of tyrosinase.
\end{abstract}

\section{Introduction}

The ability to synthesize melanin or melanin-like pigments is a common feature among Streptomyces species (Kuster, 1976); similar pigments are formed by a number of prokaryotic and eukaryotic organisms. Melanin formation from tyrosine is catalysed by the enzyme tyrosinase (o-diphenol :oxygen oxidoreductase, EC 1.14.18.1), a copper-containing monooxygenase (Lerch, 1981). The mel locus from Streptomyces antibioticus has been cloned and sequence analysis has shown that it contains two open reading frames (ORFs) (Katz et al., 1983; Bernan et al., 1985). Structural analyses of the gene and protein have established that one ORF encodes the enzyme tyrosinase $\left(M_{\mathrm{r}} 30612\right)$. The second (ORF 438) specifies a protein $\left(M_{\mathrm{r}}\right.$ 14754) the function of which is not well understood. Both ORFs may be transcribed from the same promoter (V. Bernan, unpublished results), and evidence from insertional inactivation showed that both genes are required for efficient tyrosinase expression (Katz et al., 1983). Complementation studies indicated that ORF 438 functions as a trans

\footnotetext{
- Author for correspondence. Tel. (202) 6871135 ; fax (202) 6871800.

$\dagger$ Present address: Lederle Laboratories, American Cyanamid Company, Pearl River, NY, USA.

$\ddagger$ Present address: Merck Sharp and Dohme Research Laboratories, Division of Merck and Company, West Point, PA, USA.

Abbreviations: $t s r$, thiostrepton resistance gene; $m e l$, tyrosinase structural gene; CDM, chemically defined medium; MM, minimal medium; $U$, units of enzyme activity.
}

activator of tyrosinase (Lee et al., 1988). The gene product of ORF 438 may be involved in tyrosinase secretion, and/or it may serve as a metallothionein-like protein that carries copper to apotyrosinase (Bernan et al., 1985; Lee et al., 1988). The mel locus of Streptomyces glaucescens has also been cloned and sequenced, revealing an organization corresponding to that present in $S$. antibioticus (Hintermann et al., 1985; Huber et al., 1985, 1987). Moreover, the nucleotide sequence obtained for the tyrosinase gene from $S$. antibioticus and $S$. glaucescens is remarkably similar $(>85 \%)$. Since methionine serves as inducer in both organisms, regulation of enzyme synthesis also appears to be analogous (Baumann et al., 1976; Crameri et al., 1982; Katz \& Betancourt, 1988).

In this paper we describe ${ }^{35} \mathrm{~S}$-labelling experiments and Western blot analysis that define further the characteristics of methionine induction of tyrosinase in $S$. antibioticus. In addition, examination of deletions within ORF 438 has provided evidence for the role of this region in tyrosinase activity.

\section{Methods}

Organisms and conditions of cultivation. Streptomyces antibioticus IMRU 3720 was grown on a malt extract/yeast extract/maltose agar medium (Bernan et al., 1985). For enzyme purification (see below), a $S$. antibioticus strain harbouring pIJ702 ( $t$ sr mel) was used as a source of tyrosinase. After cultivation in NZ amine medium (Katz \& Goss, 1959), washed mycelium of $S$. antibioticus was introduced into a chemically defined medium (CDM) containing, per litre: glutamic acid. $\mathrm{HCl}, 8.0 \mathrm{~g}$; asparagine, $2.0 \mathrm{~g}$; proline, $2.0 \mathrm{~g}$ and mineral salts (Katz \& Betancourt, 1988). D-Glucose (10 mM final concentration) and 

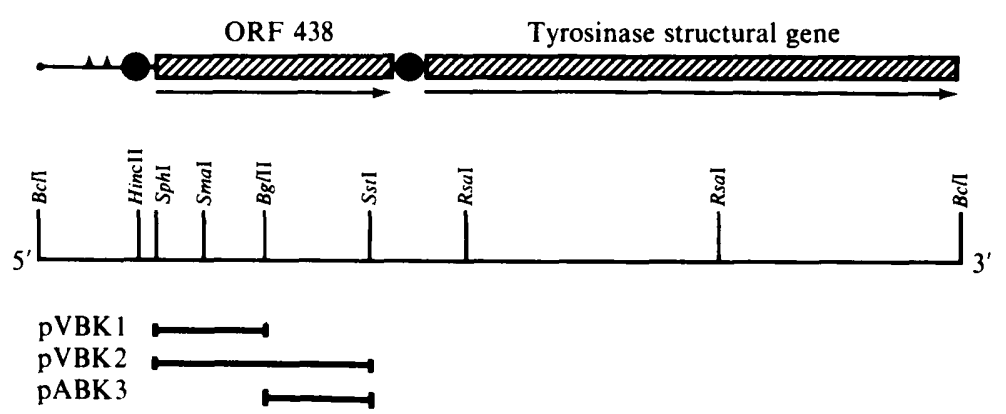

$\mathrm{CuSO}_{4} \cdot 5 \mathrm{H}_{2} \mathrm{O}(4 \mu \mathrm{M}$ final concentration) were added before inoculation. Streptomyces lividans 3131 bearing the multicopy plasmid pIJ702 and the $S$. lividans 66 strains employed were grown on $R_{2} Y E$ agar medium (Hopwood et al., 1985). Vegetative mycelium of $S$. lividans was cultivated in YEME liquid medium before incubation in CDM (Hopwood et al., 1985). Streptomyces spores were harvested and stored at $-20^{\circ} \mathrm{C}$ as described by Hopwood et al. (1985).

Chemicals and antibiotics. All chemicals were reagent grade and were purchased from commercial sources. L-Amino acids were used throughout unless specified otherwise. The antibiotics were obtained as follows: actinomycin D (Dr Anthony Mauger, Medlantic Research Foundation, Washington, DC, USA), chloramphenicol (Warner Lambert Company, Parke-Davis Division, Ann Arbor, MI, USA), thiostrepton (S. J. Lucania, Bristol-Myers Squibb Corporation, Princeton, NJ, USA). Rifampicin was purchased from Sigma.

Plasmids, transformation and other DNA procedures. The Streptomyces plasmid pIJ702 was constructed previously by subcloning the mel operon from pIJ700 into pIJ350 (tsr) (Katz et al., 1983). The plasmid constructs pVBK $1, \mathrm{pVBK} 2$ and pABK 3 were prepared by deletion of the SphI-BglII (160 bp), SphI-SstI (401 bp) or the BglII-Sst I (236 bp) region, respectively, within ORF 438 of the mel operon (pIJ702) by restriction endonuclease digestion (Fig. 1). Each linearized fragment was isolated by agarose gel electrophoresis, and following electroelution, was purified (Hopwood et al., 1985). In the case of pVBK 1 and pVBK2, the linearized fragments were filled in with Klenow fragment, whereas pABK 3 was treated with T4 DNA polymerase. The fragments were then circularized by blunt-end ligation with $\mathrm{T} 4$ ligase. Restriction endonuclease mapping confirmed that the appropriate deletion within ORF 438 had been made. Plasmid DNA was prepared as described by Hopwood et al. (1985). Transformation with plasmid DNA was carried out using protoplasts of $S$. lividans 66 (Hopwood et al., 1985). Selection of transformants was based on the growth of colonies displaying a $\mathrm{Tsr}^{+}$ $\mathrm{Mel}^{-}$phenotype on $\mathrm{R}_{2} \mathrm{YE}$ and minimal medium (MM) supplemented as described elsewhere (Katz et al., 1983).

Purification of tyrosinase. Tyrosinase was purified from the culture filtrate of $S$. antibioticus (harbouring pIJ702) previously grown in CDM for $40-44 \mathrm{~h}$. $S$. antibioticus strains bearing this plasmid, in comparison to the parental strain, synthesize high levels of the enzyme in the absence of methionine and exhibit only a one- to twofold induction with the amino acid. The enzyme was purified to apparent homogeneity in two steps by chromatography. In step 1 the filtrate containing sodium chloride $(1.0 \mathrm{M}$ final concentration) was applied to a column $(2.5 \times 35 \mathrm{~cm})$ of Phenyl Sepharose CL-4B. The column was washed with $0.05 \mathrm{M}$-sodium phosphate buffer (pH 7.2) containing $1 \mathrm{M}$-sodium chloride; enzyme activity was eluted with a gradient consisting of a decreasing concentration of sodium chloride $(1.0$ to $0.0 \mathrm{M})$ and an increasing concentration of ethylene glycol $(0 \%$ to $75 \%, v / v)$ both in $0.05 \mathrm{M}$-sodium phosphate, $\mathrm{pH} 7.2$. Active fractions were pooled, dialysed ( $0.05 \mathrm{M}$-sodium phosphate, $\mathrm{pH} 7.2)$ and concentrated by ultrafiltration using a PM-30 membrane (Amicon). In step 2 the
Fig. 1. Restriction enzyme map of the mel operon in pIJ702 (Bernan et al., 1985; Katz et al., 1983). Hatched boxes represent coding regions, circles represent ribosome-binding sites, and triangles represent -10 and -35 promoter regions. The arrows define the direction of transcription of the ORF 438 and tyrosinase structural genes. within ORF 438 that were deleted yielding the plasmids pVBK1, pVBK2 and pABK3 (see Methods). concentrated enzyme was loaded on a Sephacryl S-200 column $(1.5 \times 55 \mathrm{~cm})$ in $0.05 \mathrm{M}$-sodium phosphate buffer $(\mathrm{pH} \mathrm{7.2)}$ and eluted with the same buffer. Fractions with peak tyrosinase activity were concentrated as above. Generally, $2-3 \mathrm{mg}$ of protein was obtained from 1 litre of CDM broth; tyrosinase was purified approximately fiveto sevenfold. Sample purity and $M_{\mathrm{r}}$ were determined routinely by SDSPAGE and Coomassie blue or silver staining.

Enzyme assays. Extracellular and intracellular tyrosinase activity were measured as described in previous publications (Lerch \& Ettlinger, 1972; Katz \& Betancourt, 1988). Mycelium and the extracellular solution were separated by aspiration filtration or centrifugation $(17000 \mathrm{~g})$. Cell extracts were prepared by passing the mycelium through a French pressure cell (American Instruments Company) or by vortexing the washed mycelium with glass beads (4-5 mm) for $2 \mathrm{~min}$. Cell debris and intact cells were removed by centrifugation at $17000 \mathrm{~g}$ for $20 \mathrm{~min}$ at $4^{\circ} \mathrm{C}$.

For studies with kynurenine formamidase, phenoxazinone synthase and $\beta$-galactosidase, $S$. antibioticus IMRU 3720 was grown in a glutamic acid/histidine/fructose medium (Williams \& Katz, 1977) for $23 \mathrm{~h} ; 0.1 \mathrm{~mm}$-methionine and, in the case of $\beta$-galactosidase, $0.6 \%$ $D$-galactose were added and the incubation was resumed for $6 \mathrm{~h}$. Cell extracts and enzyme assays were carried out as previously described (Katz \& Weissbach, 1962; Brown et al., 1980; Foster \& Katz, 1981).

Analytical methods. Protein was determined by the procedure of Bradford (1976), with bovine serum albumin as standard. Densitometry of fluorograms and Western blots was performed with an LKB Ultroscan XL laser densitometer (Pharmacia-LKB).

Radiolabelling experiments. After $S$. antibioticus had grown for $16 \mathrm{~h}$ in CDM, $10 \mathrm{ml}$ portions were transferred to $50 \mathrm{ml}$ Erlenmeyer flasks. Tyrosinase was induced with methionine ( $0.1 \mathrm{~mm}$ final concentration unless specified otherwise) and incubation was resumed for $30 \mathrm{~min}$ to allow uptake of the amino acid. $\left[{ }^{35} \mathrm{~S}\right]$ Methionine $(40 \mu \mathrm{Ci} ; \mathrm{sp}$. act. $>1000 \mathrm{Ci} \mathrm{mmol}^{-1},>37 \mathrm{TBq} \mathrm{mmol}^{-1}$; ICN Biomedicals) was then added ( 0 time) and incubation was continued for up to $6 \mathrm{~h}$. Samples collected at intervals were rapidly frozen on dry ice; subsequently, they were quickly thawed and centrifuged for $2 \mathrm{~min}$ at $4{ }^{\circ} \mathrm{C}$. Phenylmethylsulphonyl fluoride (PMSF, $1 \mathrm{~mm}$ final concentration) was added to the supernatant, which was stored on ice or at $-20^{\circ} \mathrm{C}$ until further use. The mycelium was washed twice with $5 \mathrm{ml}$ cold $0.05 \mathrm{M}$-sodium phosphate buffer ( $\mathrm{pH} \mathrm{7.2)} \mathrm{containing} 0.1 \mathrm{~mm}$-methionine and $1 \mathrm{mM}$ PMSF and stored as noted for the supernatant. Mycelium was disrupted and extracts were centrifuged as described above (Enzyme assays). Initial experiments carried out under a variety of conditions indicated that there was a rapid secretion of tyrosinase during incubation at $30{ }^{\circ} \mathrm{C}$. Since $90 \%$ or more of the enzyme was found in the culture medium, only the extracellular enzyme was studied in most experiments. Freezing followed by rapid thawing of mycelium did not result in a release of intracellular tyrosinase or other enzymes (kynurenine formamidase, phenoxazinone synthase) from $S$. antibioticus. 
Preparation of antibodies. Antibodies to tyrosinase were raised in two New Zealand White male rabbits. On day 1, the rabbits were inoculated intramuscularly and intradermally with $1 \mathrm{mg}$ of the protein in Freund's adjuvant. The rabbits were given three booster injections intramuscularly over a 4-month period at 5 -week intervals with $0.5 \mathrm{mg}$ of the enzyme in Freund's incomplete adjuvant, and were bled on day 112.

Immunoprecipitation of tyrosinase. A modification of the prodecure of Springer (1987) was used. To ${ }^{35} \mathrm{~S}$-labelled tyrosinase preparations, preimmune rabbit serum and goat anti-rabbit IgG were added. The mixture was incubated at room temperature for $1 \mathrm{~h}$ and centrifuged. Anti-tyrosinase immune serum was added to the supernatant and left overnight at $4{ }^{\circ} \mathrm{C}$. The precipitate was pelleted and washed. The final pellet was dissolved in Laemmli sample buffer for SDS-PAGE.

Gel electrophoresis and Western blots. SDS-PAGE was carried out by the procedure of Laemmli (1970). The resolving gels contained $12 \%$ $(\mathrm{v} / \mathrm{v})$ acrylamide.

Western blotting of proteins after SDS-PAGE was performed essentially by the procedure of Towbin et al. (1979). Proteins were transferred from the gel to nitrocellulose paper using an LKB transphor system. Immune serum was used at 1:5000 dilution and the horseradish-peroxidase-conjugated goat anti-rabbit IgG at 1:3000 dilution. Blots were stained with $0.05 \%(w / v) 3,3^{\prime}$-diaminobenzidine dissolved in water and $0.001 \%(\mathrm{v} / \mathrm{v})$ hydrogen peroxide.

Fluorography. Polyacrylamide gels were processed for fluorography (Bonner \& Laskey, 1974) and exposed to Kodak X-Omat film $\left(-70^{\circ} \mathrm{C}\right)$.

\section{Results}

\section{De novo synthesis of tyrosinase}

Physiological experiments have previously shown that tyrosinase activity increases following the addition of methionine to cultures of $S$. antibioticus IMRU 3720 grown in CDM (Katz \& Betancourt, 1988). To establish whether enhanced activity was the result of de novo synthesis of the enzyme or activation of an inactive proenzyme, a culture of this organism was supplemented with ${ }^{35}$ S-labelled methionine $30 \mathrm{~min}$ after addition of $0.1 \mathrm{~mm}$-methionine and incubated for an additional $5 \mathrm{~h}$. From the results in Fig. 2 it appears that de novo synthesis of tyrosinase had occurred. Densitometric analysis of the fluorogram revealed that the labelled enzyme increased sevenfold after induction.

\section{Time course of enzyme synthesis}

When extracellular tyrosinase synthesis in S. antibioticus was examined in the presence of $\left[{ }^{35} S\right]$ methionine at intervals after induction, a significant lag occurred before ${ }^{35} \mathrm{~S}$-labelled tyrosinase was seen (Fig. 3). The increase of labelled tyrosinase relative to the control at $6 \mathrm{~h}$ was about fivefold; measurement of enzyme activity (data not shown) correlated closely with the fluorographic and densitometric data.

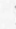
2

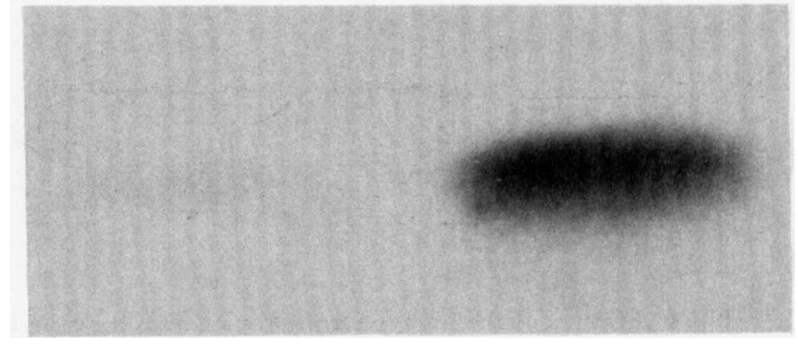

Fig. 2. Effect of methionine on de novo synthesis of tyrosinase by $S$. antibioticus IMRU 3720. Fluorogram showing radioimmunoprecipitated extracellular tyrosinase after $5 \mathrm{~h}$ incubation without (lane 1) or with (lane 2) $0.1 \mathrm{~mm}$-methionine. See Methods (Radiolabelling experiments) for details. Following immunoprecipitation, SDS-PAGE was carried out by the procedure of Laemmli (1970). Gels were processed for fluorography and exposed to Kodak X-Omat film $\left(-70^{\circ} \mathrm{C}\right)$

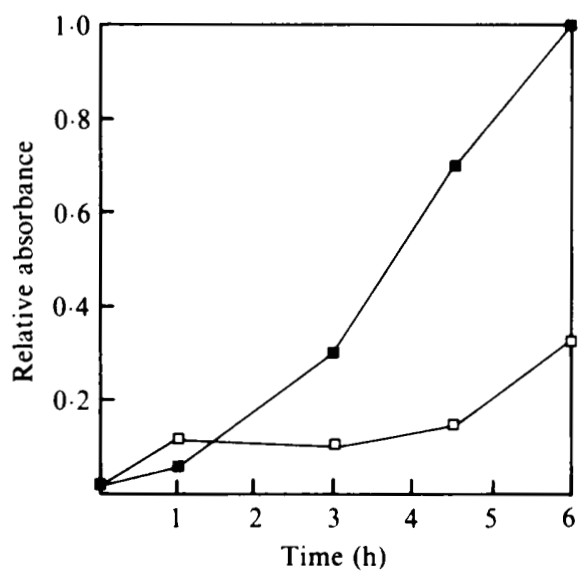

Fig. 3. Time course of tyrosinase induction with methionine. $S$. antibioticus was grown in CDM; after $16 \mathrm{~h}$, cultures were incubated without $(\square)$ and with $(\square) 0.1 \mathrm{~mm}$ methionine. Procedure as in Fig. 2 except that incubation with ${ }^{35}$ S $]$ methionine was for $6 \mathrm{~h}$. Relative absorbance refers to the absorbance obtained for a particular sample after a densitometric scan of the fluorogram.

\section{Influence of methionine concentration}

The influence of methionine concentration on tyrosinase induction was first examined by fluorography of the immunoprecipitates followed by a densitometric scan. This analysis suggested that enzyme synthesis peaked at $0.01 \mathrm{~mm}$-methionine; however, maximum enzyme activity was seen at $0.1 \mathrm{mM}$. The difference might have been due to dilution of the ${ }^{35}$ S $]$ methionine by the unlabelled methionine used as inducer. This question was resolved by Western blot analysis as shown in Fig. 4: maximal synthesis was found at $0.1 \mathrm{~mm}$-methionine, in agreement with the enzyme assays. 


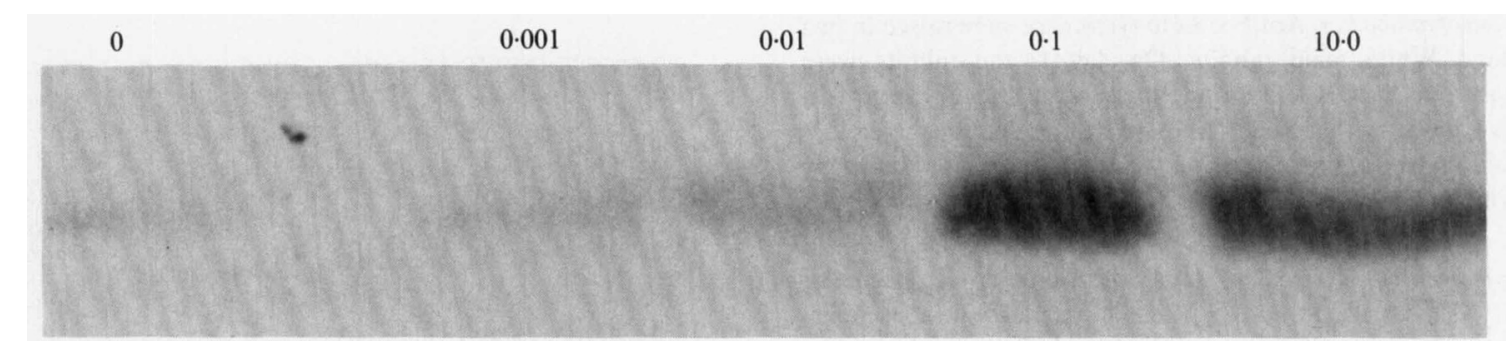

Fig. 4. Effect of methionine concentration on tyrosinase synthesis. The results shown are a Western blot of extracellular tyrosinase from $S$. antibioticus incubated for $5 \mathrm{~h}$ with no methionine $(0)$ or increasing amounts of methionine $(0.001-10.0 \mathrm{mM})$.

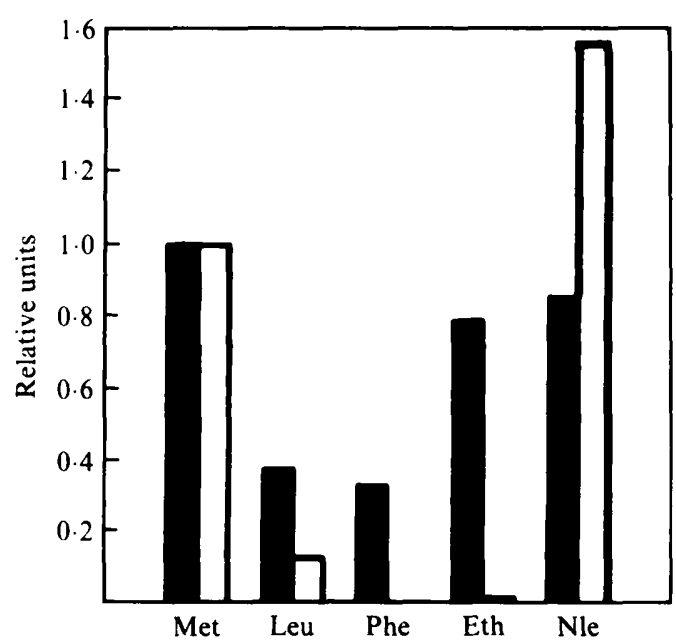

Fig. 5. Influence of various amino acids upon tyrosinase induction in cultures of $S$. antibioticus. Radiolabelling as in Fig. 2. ${ }^{35} \mathrm{~S}$-labelled samples were taken $5 \mathrm{~h}$ after the addition of : $0.1 \mathrm{~mm}$-methionine (Met), 0.1 mM-leucine (Leu), 0.1 mM-phenylalanine (Phe), $0.1 \mathrm{~mm}$-ethionine (Eth), or $0.2 \mathrm{mM}$-DL-norleucine (Nle). $\square$, Tyrosinase activity; absorbance value obtained after densitometric scanning of the fluorogram. The results are relative to methionine $(=1 \cdot 0)$.

\section{Specificity of tyrosinase induction}

The specificity of tyrosinase induction was examined using a number of amino acids, including the methionine analogues ethionine and DL-norleucine (Fig. 5). Fluorograms and immunoblots revealed that induction of enzyme synthesis was highest with methionine, DL-norleucine and ethionine. Considerably less enzyme was formed when leucine or phenylalanine was employed and no tyrosinase synthesis occurred with tyrosine, alanine or glutamic acid (data not shown). Measurement of enzyme activity indicated that only methionine and DL-norleucine evoked the synthesis of functional enzyme protein. Incorporation of ethionine into newly synthesized tyrosinase may result in the formation of a catalytically inactive protein.

To establish whether the induction with methionine was unique to the tyrosinase system, we also studied its influence on the synthesis of an inducible $\beta$-galactosidase and two key enzymes (kynurenine formamidase and phenoxazinone synthase) in actinomycin formation by $S$. antibioticus. No increase was seen in the level of kynurenine formamidase or phenoxazinone synthase activity when the culture was supplemented with methionine. By comparison, cultures induced with D-galactose plus methionine exhibited a fivefold elevation in $\beta$-galactosidase activity (sp. act. $1.43 \mathrm{U} \mathrm{mg}^{-1}$ ) versus those receiving galactose alone (sp. act. $0.27 \mathrm{U} \mathrm{mg}^{-1}$ ).

\section{Influence of $\mathrm{Cu}^{2+}$ on tyrosinase formation}

Tyrosinase is a metalloprotein that requires two atoms of copper per molecule for activity (Lerch, 1981). To determine whether methionine can induce tyrosinase in the absence of the cation, glassware and CDM were treated with Chelex 100, a $\mathrm{Cu}^{2+}$-chelating resin. Chelextreated CDM was then inoculated with washed mycelium of $S$. antibioticus and incubated at $30^{\circ} \mathrm{C}$.

Three sets of conditions were used for the induction experiment. Cultures received: (1) no $\mathrm{Cu}^{2+}$, (2) $\mathrm{Cu}^{2+}$ at the time of inoculation, or (3) $\mathrm{Cu}^{2+}$ at the time of induction. Cultures induced with methionine but receiving no copper (condition 1) exhibited negligible tyrosinase activity (sp. act. $4.0 \mathrm{U} \mathrm{mg}^{-1}$ ); however, the amount of apotyrosinase synthesized (Fig. 6) was approximately $70 \%$ of that formed when $\mathrm{Cu}^{2+}$ was added at the time of induction (condition 3 ). When copper was added at the time of inoculation (condition 2) synthesis (following induction) was about $80 \%$ of that observed under condition 3; enzyme activity in this case compared favourably (sp. act. $125 \mathrm{U} \mathrm{mg}^{-1}$ ) with the culture receiving $\mathrm{Cu}^{2+}$ at the time of induction (sp. act. $128 \mathrm{U} \mathrm{mg}^{-1}$ ).

\section{Effect of inhibitors of transcription and translation}

$S$. antibioticus cultures grown in CDM were treated with actinomycin D, rifampicin or chloramphenicol $5 \mathrm{~min}$ before induction with methionine and the addition of 


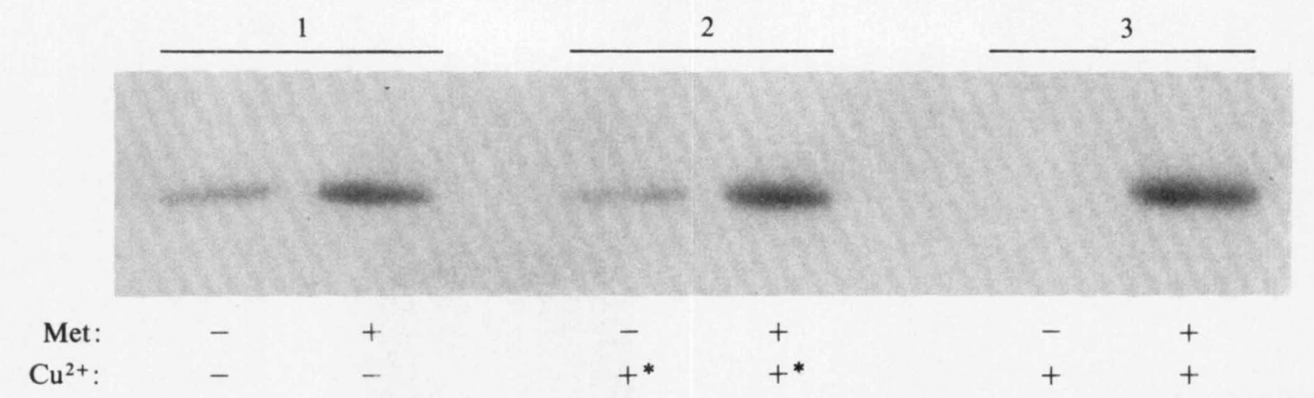

Fig. 6. Effect of $\mathrm{Cu}^{2+}$ on formation of tyrosinase. The fluorogram shows radioimmunoprecipitated samples of extracellular tyrosinase from $S$. antibioticus grown in CDM containing: 1 , no $\mathrm{Cu}^{2+}(-) ; 2, \mathrm{Cu}^{2+}$ added at inoculation $\left(+{ }^{*}\right)$; and $3, \mathrm{Cu}^{2+}$ added at induction ( + ). Tyrosinase was induced with $0.1 \mathrm{~mm}$-methionine where indicated $(+)$; after $30 \mathrm{~min}^{35} \mathrm{~S}$-methionine was added and the incubation was resumed for $4.5 \mathrm{~h}$.

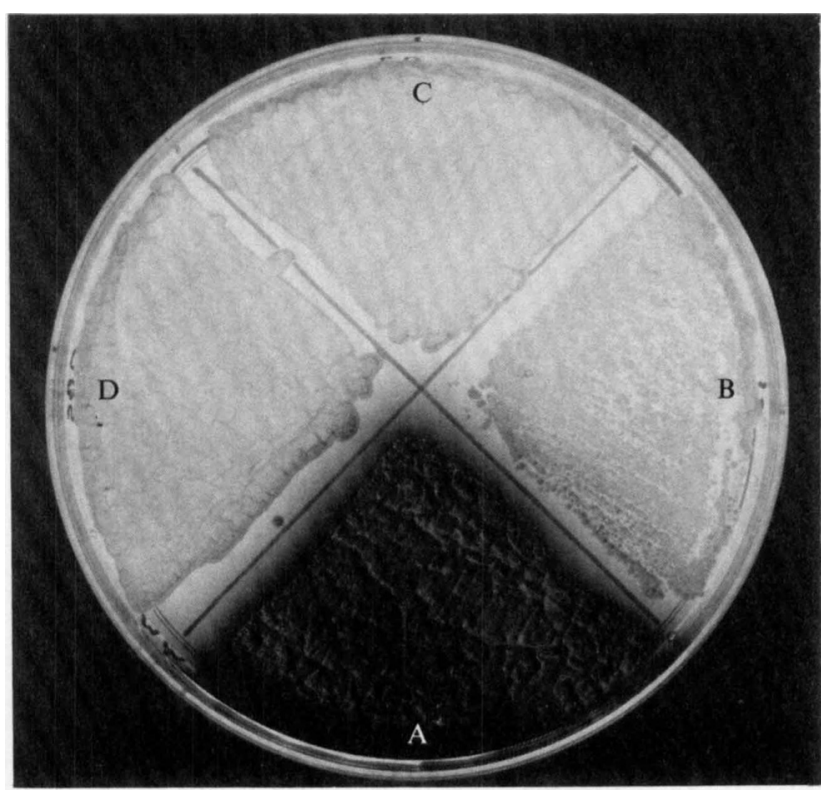

Fig. 7. Phenotypic expression of melanin in $S$. lividans $A$, S. lividans 3131(pIJ702). B-D, S. lividans 66 with: B, pVBK 1; C, pVBK2; and D, pABK3. Cultures were grown on $M M$ supplemented with tyrosine, $\mathrm{Cu}^{2+}$, thiostrepton, etc. as described by Katz et al. (1983).

${ }^{[35}$ S]methionine. Since tyrosinase was synthesized only in the culture incubated without antibiotic (data not shown), it was concluded that both transcriptional and translational events are required.

\section{Role of ORF 438}

To assess the role of ORF 438, deletion plasmids (pVBK1, pVBK2 and pABK3) derived from pIJ702 were constructed and introduced into $S$. lividans 66 as described in Methods. Fig. 7 shows the growth of $S$. lividans 66 harbouring each of the deletion plasmids, and S. lividans 3131(pIJ702), on MM agar supplemented with tyrosine and copper (Katz et al., 1983). Melanin formation was observed only with $S$. lividans 3131(pIJ702).

The ORF 438 deletions in pVBK1, pVBK2 and pABK 3 greatly diminished tyrosinase synthesis in comparison to that by $S$. lividans containing pIJ702. The deletion within $\mathrm{pVBK} 1$ yielded a nonsense mutation, whereas the deletions in pVBK2 and pABK3 each resulted in a frameshift mutation. In addition, $\mathrm{pVBK} 1$ and pVBK 2 lack the ORF 438 initiation codon. Thus, the decreased amount of tyrosinase formed may be attributable to genetic polarity and/or instability of the transcript synthesized (Watson et al., 1987).

No discernible tyrosinase activity was detected in the extracellular filtrates from $S$. lividans strains harbouring the deletion plasmids (even after 30 -fold concentration) (Table 1). By comparison, considerable extracellular tyrosinase activity was present in $S$. lividans 3131(pIJ702) (total 3.16 U). Intracellular tyrosinase activity [ 5 to $10 \%$ of the total extracellular activity of S. lividans 3131(pIJ702)] was found in extracts of the $S$. lividans strains harbouring pVBK1 (total $0.29 \mathrm{U}$ ), pVBK2 $(0.28 \mathrm{U})$, pABK $3(0.29 \mathrm{U})$ or pIJ702 $(0.37 \mathrm{U})$. Western blot analysis of extracellular filtrates from the deletion mutants revealed that there was a small amount of immunoreactive protein (pABK3 > pVBK2 > $\mathrm{pVBK} 1$ ) with an $\boldsymbol{M}_{\mathrm{r}}$ comparable to that of the tyrosinase from $S$. lividans 3131 and $S$. antibioticus (Fig. 8 b). Similar results were obtained from an immunoblot of intracellular extracts (Fig. 8d). Interestingly, the level of immunoreactive tyrosinase with pABK 3 (Fig. $8 d$, lane 4, Table 1) was 1.5 times that found with pIJ702 (lane 5). Addition of $\mathrm{Cu}^{2+}(4 \mu \mathrm{M}$ final concentration) to intracellular extracts from the strain bearing pABK 3 stimulated enzyme activity approximately twofold, suggesting that some of the protein synthesized was apotyrosinase. This effect was not seen when $\mathrm{Zn}^{2+}, \mathrm{Co}^{2+}, \mathrm{Fe}^{2+}$ or $\mathrm{Mg}^{2+}$ was substituted for $\mathrm{Cu}^{2+}$. Moreover, no increase in 


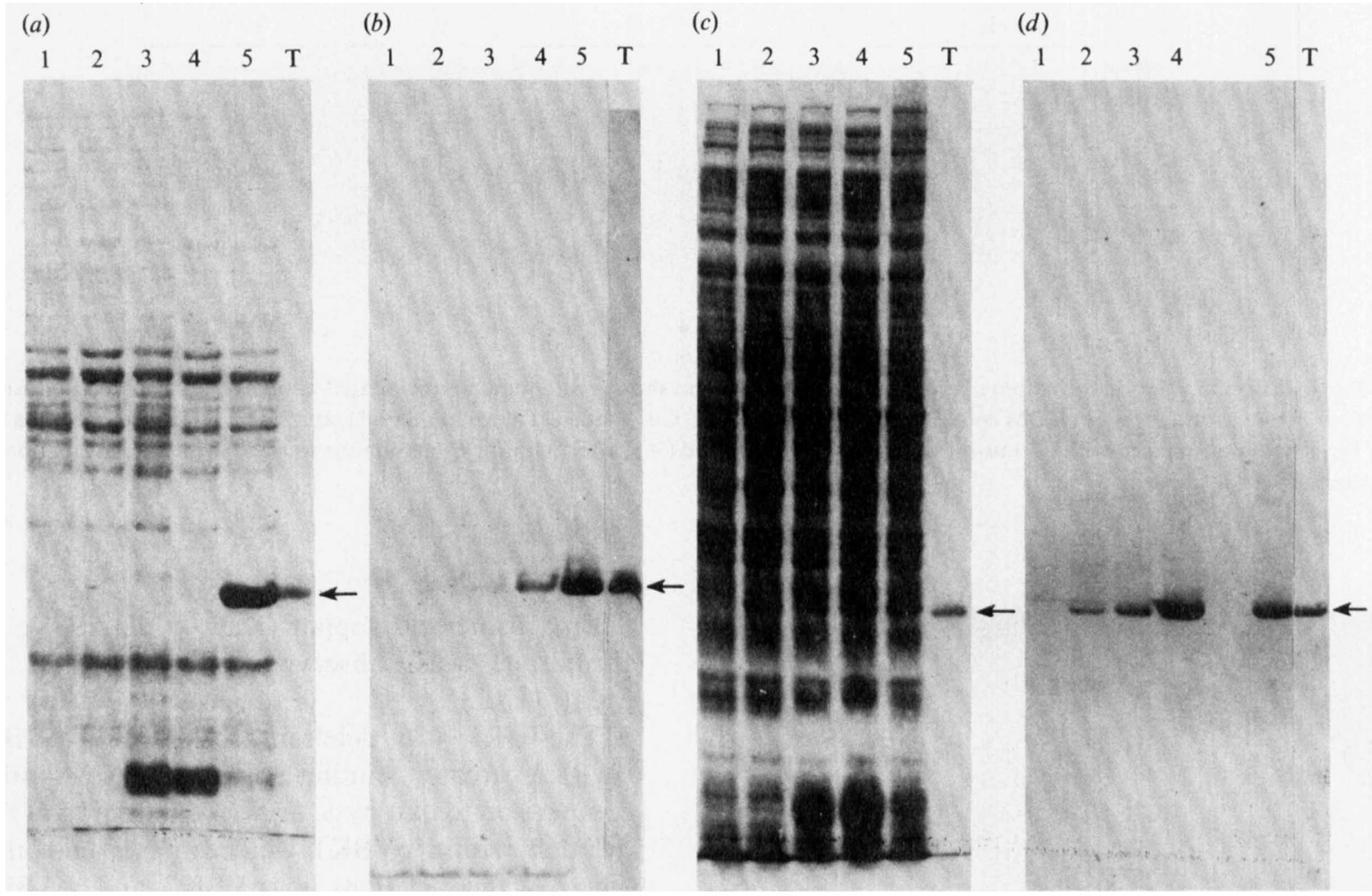

Fig. 8. SDS-PAGE $(a, c)$ and Western blot $(b, d)$ analysis of tyrosinase synthesized by $S$. lividans 66 strains with: (1) no plasmid, (2) pVBK 1, (3) pVBK2, (4) pABK3, and (5) pIJ702. Ten micrograms of protein were used in each lane except in the case of pIJ702 (panel $b$, lane 5) and $\mathrm{T}$ (panels $b$ and $d$ ), where $4 \mu \mathrm{g}$ and $1 \mu \mathrm{g}$ were loaded, respectively. Lanes $\mathrm{T}$ contain the tyrosinase purified from $S$. antibioticus (arrowed). $(a, b)$ Extracellular tyrosinase (concentrated 30-fold with an Amicon Centriprep-10 concentrator); $(c, d)$ intracellular tyrosinase. Gels (panels $a$ and $c$ ) were stained with Coomassie blue R-250.

Table 1. Tyrosinase activity in $S$. lividans strains harbouring pIJ702 or the deletion plasmids

Enzyme activity measurements and Western blots were carried out as described in Methods. Tyrosinase activity is expressed as specific activity $\left(\mathrm{U} \mathrm{mg}^{-1}\right)$. The relative amount of tyrosinase (column 4) was determined by densitometric scanning of the Western blots (Fig. $8 b, d$ ) and normalized to $S$. lividans 3131(pIJ702). The S. lividans 66 strains used harboured no plasmid (None), pVBK 1, pVBK 2 or pABK3.

\begin{tabular}{lllc}
\hline \hline Source & Plasmid & $\begin{array}{c}\text { Tyrosinase } \\
\text { activity }\end{array}$ & $\begin{array}{c}\text { Relative } \\
\text { absorbance }\end{array}$ \\
\hline Intracellular & None & 0.00 & 0.00 \\
& pVBK1 & 0.005 & 0.33 \\
& pVBK2 & 0.008 & 0.49 \\
& pABK3 & 0.008 & 1.48 \\
Extracellular & pIJ702 & 0.008 & 1.00 \\
& None & 0.00 & 0.00 \\
& pVBK1 & 0.00 & 0.03 \\
& pVBK2 & 0.00 & 0.04 \\
& pABK3 & 0.00 & 0.07 \\
& pIJ702 & 1.00 & 1.00 \\
\hline \hline
\end{tabular}

enzyme activity was observed when $\mathrm{Cu}^{2+}$ was added to extracts from $S$. lividans 3131 (pIJ702). Similar experiments were not carried out with extracts obtained from $S$. lividans strains carrying $\mathrm{pVBK} 1$ or $\mathrm{pVBK} 2$.

A prominent protein band (about $16 \mathrm{kDa}$ ) was evident in SDS-PAGE gels of intracellular and extracellular preparations (pVBK2 and pABK3, Fig. $8 a, c$, lanes 3 and 4). As this protein did not correspond in size to that expected of a truncated ORF 438 gene product and did not react with anti-tyrosinase sera, further investigations were not undertaken.

\section{Discussion}

In a previous investigation we examined the physiological conditions that favour tyrosinase synthesis by $S$. antibioticus (Katz \& Betancourt, 1988). These studies revealed that young cells $(15-20 \mathrm{~h})$ are required and that enzyme induction appears to be specific for methionine. 
$\mathrm{Cu}^{2+}$ was also essential for functional enzyme activity. In the present study, tyrosinase synthesis by $S$. antibioticus was examined using $\left[{ }^{35}\right.$ S $]$ methionine and Western blotting. To minimize the effect of dilution, $\left[{ }^{35} \mathrm{~S}\right]-$ methionine was added 30 min post-induction to allow uptake of the unlabelled methionine. Although we anticipated a major problem with dilution of the $\left[{ }^{35}\right.$ S]methionine when the unlabelled amino acid was employed as inducer, this difficulty did not arise in most experiments. It was shown that de novo synthesis of the enzyme occurs as a function of time and methionine concentration, and appears to be relatively specific for this amino acid and some closely related analogues. Induction with ethionine or norleucine may be an indirect effect; utilization of these compounds in metabolism (e.g. protein synthesis) may spare endogenous methionine, permitting its use for induction.

Under the conditions employed, tyrosinase was secreted rapidly, with little intracellular accumulation. Although $\mathrm{Cu}^{2+}$ is essential for the synthesis of catalytically active enzyme, apotyrosinase is synthesized at appreciable levels $(70 \%$ of control) upon induction in the absence of the copper. In contrast to the previous results with S. michiganensis (Held \& Kutzner, 1990), induction of tyrosinase synthesis with $\mathrm{Cu}^{2+}$ in the absence of methionine was not observed. In addition to its role as an activator of apotyrosinase, $\mathrm{Cu}^{2+}$ may stabilize the protein; this could account for the enhanced enzyme activity seen when $\mathrm{Cu}^{2+}$ was provided to cultures of $S$. michiganensis. It was also evident from the experiments with inhibitors that both transcriptional and translational events are required for tyrosinase induction in $S$. antibioticus.

The role of the open reading frame (ORF 438) upstream of the tyrosinase structural gene has been the subject of considerable speculation since the nucleotide sequence of the mel locus was first established (Bernan et al., 1985). It has been proposed that the gene product of ORF 438 may function in tyrosinase secretion and/or may serve to carry $\mathrm{Cu}^{2+}$ to the apoenzyme (Bernan et al., 1985; Lee et al., 1988). The present investigations with the deletion plasmids suggest that ORF 438 may, indeed, function in the export of tyrosinase. Thus, virtually no tyrosinase was present in the extracellular medium (Fig. $8 b$ ) and accumulation of the protein intracellularly was even greater with pABK 3 than with pIJ702 (Fig. $8 d$, Table 1). This result would suggest an impairment of the translocation process. In contrast to most secreted proteins, tyrosinase, purified from either $S$. antibioticus or $S$. glaucescens, does not possess a signal peptide; the intracellular and extracellular forms of the enzyme are identical in $M_{\mathrm{r}}$ and $\mathrm{N}$-terminal amino acid sequence (Crameri et al., 1982; Bernan et al., 1985). Moreover, the amino acid sequence deduced from the nucleotide sequence of the mel operon cloned from these organisms (Bernan et al., 1985; Huber et al., 1985) concurred with the corresponding protein sequence. Although there is precedence for secretion of proteins that lack a leader sequence, other proteins may be required to facilitate export in prokaryotes (Pugsley et al., 1990). ORF 438 specifies a protein whose $\mathrm{N}$-terminal signal sequence is characteristic of secreted proteins. Conceivably, the ORF 438 gene product serves in $S$. antibioticus as a translocation protein for the export of tyrosinase.

Lee et al. (1988) reported that ORF 438 codes for a trans-acting factor and suggested that it may facilitate the transfer of $\mathrm{Cu}^{2+}$ to the apotyrosinase. The possibility that the ORF 438 protein participates in the transfer of $\mathrm{Cu}^{2+}$ to the apotyrosinase to activate the enzyme was supported by our observation that addition of $\mathrm{Cu}^{2+}$ stimulated tyrosinase activity twofold in extracts derived from $S$. lividans harbouring pABK3. Recently, della Cioppa et al. (1990) reported the cloning of the mel fragment from plJ702 into a bacteriophage T7 promoter vector. Their studies with Escherichia coli using deletion analyses revealed that a functional ORF 438 protein is required for catalytically active tyrosinase. It was also shown that expression of ORF 438 (in the mel locus) was necessary for high-level melanin formation in $E$. coli. Similar results were obtained in our investigations with the deletion plasmids in S. lividans (Fig. 7). Although these initial experiments suggest a dual role for the ORF 438 gene product, further molecular and biochemical experiments are needed to establish its function in the phenotypic expression of tyrosinase.

Expression of several genes in E. coli and its bacteriophages or transposons is influenced by DNA methylation (Sternberg, 1985; Marinus, 1987). We have previously hypothesized that induction of tyrosinase with methionine ( $S$. antibioticus) may require the methylation of specific residues flanking the promoter region of the mel operon (Katz \& Betancourt, 1988). Geistlich et al. (1989) have proposed that a putative protein represses tyrosinase expression in the absence of inducer and that repression can be removed by the presence of inducer or by deleting the repressor-binding site. Although experimental evidence is needed to verify this hypothesis, methionine (or possibly $S$-adenosylmethionine) may serve as a regulatory signal at the level of transcription in the synthesis of inducible enzymes in Streptomyces.

Whether the organization of the mel operon and the regulation of its expression in different species of Streptomyces are the same as described for $S$. antibioticus and $S$. glaucescens is not well established. Recently, Held \& Kutzner (1990) reported that $\mathrm{Cu}^{2+}$ induces tyrosinase formation in $S$. michiganensis and that the system is not regulated by methionine, indicating that there are 
different signals that control tyrosinase formation. However, similarities in gene organization are suggested by hybridization experiments which have shown that a gene related to the $S$. antibioticus ORF 438 may be present in genomic DNA from $S$. michiganensis.

We wish to thank Lederle Laboratories, American Cyanamid Co., for a fellowship grant (W.H.). We also acknowledge Mr S. J. Lucania, Bristol-Myers Squibb Co. for a generous supply of thiostrepton. We would also like to thank $\operatorname{Dr} \mathrm{H}$. B. Herscowitz and Dr M. F. Cole, Georgetown University, for their valuable advice and assistance in the preparation of tyrosinase antisera and in other immunological techniques.

\section{References}

Baumann, R., Ettlinger, L., Hütter, R. \& Kocher, H. P. (1976). Control of melanin formation in Streptomyces glaucescens. In Actinomycetes - the Boundary Organisms, pp. 55-63. Edited by T. Arai. Tokyo, Japan: Toppan Company.

Bernan, V., Fipula, D., Herber, W. \& Katz, E. (1985). The nucleotide sequence of the tyrosinase gene from Streptomyces antibioticus and characterization of the gene product. Gene 37, 101-110.

BonNer, W. M. \& Laskey, R. A. (1974). A film detection method for tritium-labelled proteins and nucleic acids in polyacrylamide gels. European Journal of Biochemistry 46, 83-88.

BRADFORD, M. M. (1976). A rapid and sensitive method for the quantitation of microgram quantities of protein utilizing the principle of protein-dye binding. Analytical Biochemistry 72, 248-254.

Brown, D. D., HitchCock, M. J. M. \& KATZ, E. (1980). Evidence for a constitutive and inducible form of kynurenine formamidase in an actinomycin-producing strain of Streptomyces parvulus. Archives of Biochemistry and Biophysics 202, 18-22.

della Cioppa, G., Garger, S. J., Sverlow, G. G., Turpen, T. H. \& GriLL, L. K. (1990). Melanin production in Escherichia coli from a cloned tyrosinase gene. Bio/Technology 8, 636-638.

Crameri, R., Ettlinger, L., Hütter, R., Lerch, K., Suter, M. A. \& VeTTERLI, J. A. (1982). Secretion of tyrosinase in Streptomyces glaucescens. Journal of General Microbiology 128, 371-379.

FosTER, J. W. \& KATZ, E. (1981). Control of actinomycin D biosynthesis in Streptomyces parvulus: regulation of tryptophan oxygenase activity. Journal of Bacteriology 148, 670-677.

Geistlich, M., IRNIGer, S. \& HÜtTER, R. (1989). Localization and functional analysis of the regulated promoter from the Streptomyces glaucescens mel operon. Molecular Microbiology 3, 1061-1069.

HeLD, T. \& KUTZNER, H. (1990). Transcription of the tyrosinase gene in Streptomyces michiganensis DMS 40015 is induced by copper and repressed by ammonium. Journal of General Microbiology 136, 2413-2419.

HintermanN, G., Zatchej, M. \& HÜtter, R. (1985). Cloning and expression of the genetically unstable tyrosinase structural gene from Streptomyces glaucescens. Molecular and General Genetics 200, $422-432$.
Hopwood, D. A., Bibb, M. J., Chater, K. F., Kieser, T., Bruton, C. J., Kieser, H. M., Lydiate, D. J., SMith, C. P., WARD, J. M. \& SCHREMPF, H. (1985). In Genetic Manipulation of Streptomyces - a Laboratory Manual. Norwich: John Innes Foundation.

Huber, M., HintermanN, G. \& LerCh, K. (1985). Primary structure of tyrosinase from Streptomyces glaucescens. Biochemistry 24, 6038-6044.

Huber, M., HÜtTER, R. \& LeRCH, K. (1987). The promoter of the Streptomyces glaucescens mel operon. Nucleic Acids Research 15, 8106.

KATZ, E. \& Betancourt, A. (1988). Induction of tyrosinase by L-methionine in Streptomyces antibioticus. Canadian Journal of Microbiology 34, 1297-1303.

KATZ, E. \& Goss, W. A. (1959). Controlled biosynthesis of actinomycin with sarcosine. Biochemical Journal 73, 458-465.

KATZ, E. \& Weissbach, H. (1962). Biosynthesis of the actinomycin chromophore; enzymatic conversion of 4-methyl-3-hydroxyanthranilic acid to actinocin. Journal of Biological Chemistry 237, 882-886.

KatZ, E., Thompson, C. J. \& Hopwood, D. A. (1983). Cloning and expression of the tyrosinase gene from Streptomyces antibioticus in Streptomyces lividans. Journal of General Microbiology 129, 2703-2714.

KUSTER, E. (1976). Chromogenicity of actinomycetes. In Actinomycetes - the Boundary Organisms, pp. 43-54. Edited by T. Arai. Tokyo, Japan: Toppan Company.

LAEMMLI, U. K. (1970). Cleavage of structural proteins during the assembly of the head of bacteriophage T4. Nature, London 227, $680-685$.

LEE, Y.-H. W., CheN, B.-F., Wu, S.-Y., LeU, W.-M., LiN, J.-J., CHEN, C. W. \& Lo, S. J. (1988). A trans-acting gene is required for the phenotypic expression of a tyrosinase gene in Streptomyces. Gene 65, 71-81.

LERCH, K. (1981). Copper monooxygenases: tyrosinase and dopamine $\beta$ monooxygenase. In Metal Ions in Biological Systems, vol. 13, pp. 143-184. Edited by H. Sigel. New York: Marcel Dekker.

LERCH, K. \& ETrLINGER, L. (1972). Purification and characterization of tyrosinase from Streptomyces glaucescens. European Journal of Biochemistry 31, 427-437.

MARINUs, M. G. (1987). DNA methylation in Escherichia coli. Annual Reviews of Genetics 21, 113-131.

Pugsley, A. P., D'Enfert, C., Reyss, I. \& Kornacker, M. G. (1990). Genetics of extracellular protein secretion by gram-negative bacteria. Annual Review of Genetics 24, 67-90.

SPRINGER, T. A. (1987). Immunoprecipitation. In Current Protocols in Molecular Biology, Chapter 10, 10.16. Edited by F. M. Ausubel. New York: Greene Publishing Association \& Wiley Interscience.

STERNBERG, N. (1985). Evidence that adenine methylation influences DNA-protein interactions in Escherichia coli. Journal of Bacteriology 164, 490-493.

Towbin, H., Staehelin, T. \& Gordon, J. (1979). Electrophoretic transfer of proteins from polyacrylamide gels to nitrocellulose sheets: procedure and some applications. Proceedings of the National Academy of Sciences of the United States of America 76, 4350-4354.

Watson, J. D., Hopkins, N. H., Roberts, J. W., Steitz, J. A. \& WEINER, A. M. (editors) (1987). Regulation of protein synthesis and function in bacteria. In Molecular Biology of the Gene, 4th edn, pp. 465-502. Reading, MA: Benjamin/Cummings Publishing Co.

Williams, W. K. \& KatZ, E. (1977). Development of a chemically defined medium for the synthesis of actinomycin D by Streptomyces parvulus. Antimicrobial Agents and Chemotherapy 11, 281-290. 